\title{
The Design of an In Vitro Fertilization (IVF) Laboratory and its Importance in Risk Prevention: Applicability of UV Radiation
}

\author{
Enrique Gea Izquierdo ${ }^{1 *}$, Carlos Ángel Benavides Velasco ${ }^{2}$, José Vicente Maeso Escudero ${ }^{3}$ \\ and Antonio García Rodríguez ${ }^{3}$ \\ ${ }^{1}$ Social Security Entity for Studies on Work Accidents and Professional Diseases, 11; c/ Hilera, 15; 29007; Málaga - \\ Spain; ${ }^{2}$ Center of Quality and Strategic Planning; University of Malaga; Campus El Ejido; 29071; Málaga - Spain \\ ${ }^{3}$ Chair of Work Safety and Health; Labour Risk Prevention; University of Malaga; Campus El Ejido;, 29071; \\ Málaga - Spain
}

\begin{abstract}
This study addressed the environmental control of an IVF laboratory and the potential repercussions that the presence of certain physical, chemical and biological agents could have on workers' health or on the tasks they carried out. The design of the laboratory and its facilities contributed to an improvement in work quality and minimised the environmental-related risks. The preventive measures adopted had an influence on the carried out actions.
\end{abstract}

Key words: Environmental control, IVF laboratory, design, facilities, UV radiation

\section{INTRODUCTION}

The use of non-ionising radiation is now fairly widespread. Of all the different types, there is a special focus on ultraviolet radiation (UV), since it has many applications, especially in the pharmaceutical and food industries, hospitals, etc. UV lamps have been used in American hospitals for reducing the number of airborne bacteria in operation theatres since the 1930s (Bintsis et al., 2000). More recently, UV radiation has been used on a specific substrate for eliminating different outdoor pollutants (Ichiura et al., 2003).

The approach presented here looked into the possibility of using a band of the UV spectrum in hospitals and, more specifically, in laboratories.
Without forgetting the application of radiation on the surfaces for germicidal purposes, the object of this study was to control the airborne biological agents. Further, in line with the innovative designs that have recently been used in the construction of IVF laboratories (Worrilow et al., 2000), the design of an IVF laboratory with optimum environmental control is presented.

The UV spectrum lies in the range of $100-400 \mathrm{~nm}$. Special attention is given to UV-C (100-280 nm), which is highly efficient as a germicide and for improving indoor air quality (Scheir and Fencl, 1996) and which otherwise does not penetrate most substances. Suntanned people can tolerate skin exposure surpassing the threshold limit values (TLVs) without erythematous effects, although

*Author for correspondence: enriquegea@telefonica.net 
this acclimatisation does not protect against skin cancer. After irradiation, a substantial increase in protein loss in water has been reported (Santos Nogueira and Joekes, 2004). Among the hundreds of agents that can cause hypersensitivity to UV radiation are certain plants and compounds, such as antibiotics (tetracycline, sulphathiazole, etc.), some antidepressants (imipramine, sinequan, etc.) and diuretics, antipsychotic drugs, cosmetics, specific colorants, lime oil or distilled coal tar (ACGIH, 1998).

In the approach considered here, the germicidal action originates from the radiation emitted by a mercury-vapour arc lamp, burning at low pressure. Short-wave UV radiation passes through a special lens (made of hard quartz and free of phosphorus) that permits the total propagation of radiation. It is held that $95 \%$ of the energy emitted by a germicide lamp has a wavelength of $253.7 \mathrm{~nm}$, with a germicidal action of $80 \%$. Photolytic processes alter the cellular structure of DNA and RNA (nucleic acids, thymine and cytosine), having a lethal or sublethal effect on the microorganisms (Morgan, 1989). To completely sterilise the air contained in a large room, it would have to be radiated continuously in hermetic conditions which is practically impossible.

One of the areas of major concern is the negative impact of the quality of water used in the preparation of culture media and exposure conditions on embryonic development (Wiemer et al, 1998). It is important to control the wavelength in the range of $254 \mathrm{~nm}$, without letting it drop below $250 \mathrm{~nm}$ since this could lead to UV-C oxidation, which can be avoided by controlling the volatile organic compounds (VOCs) (Heinsohn et al, 1994). Generally speaking, precautions must be taken when using UV-C radiation in the presence of people, as prolonged exposure can cause erythemas and conjunctivitis, whereas UV radiation below TLV exposure, in conjunction with external or systematic exposure to a series of chemical compounds, can lead to dermic erythema (ACGIH, 1998).

\section{$\mathrm{UV}$ radiation as an antibacterial agent}

Both irradiance and exposure time are used to calculate the radiation dose. Nevertheless, the system's effectiveness depends on air quality. The factors that most affect the lamp performance are as follows:
- Suspension particles: the number can increase due to the disturbance of surface dust during the cleaning procedures, the defective design or lack of maintenance of air filters, specific external processes affecting indoor air quality, etc. Particles can interact in the radiation of micro-organisms, since these can shield themselves when airborne. There is in fact a correlation between the size of particles and that of bacteria (Klánová, 2003). The presence of particles and VOCs can influence the rate of implantation and embryogenesis (Worrilow et al, 2001).

- Temperature is a determining factor. The optimum operating temperature for lamps is around $40^{\circ} \mathrm{C}$, with a room temperature of $20^{\circ} \mathrm{C}$. In fact, UV levels will fluctuate at high or excessively low temperature levels (Philips, 1985).

An air velocity (Real Decree $\left.n^{\circ} .486,1997\right)$ of 0.5 $\mathrm{m} / \mathrm{s}$ has been measured for sedentary works in warm working environments. As can be seen in Figure 1, there is a clear relation between the temperature increase and constant air velocity in relation to the percentage of $254 \mathrm{~nm}$ UV radiation emissions.

- Another main problem is dust deposition on lamp surfaces, which will be discussed later on.

- By keeping the relative humidity between 40 and $60 \%$, fungi growth is minimised (INSALUD, 1999) and radiation effectiveness maximised (with relative humidity values below $60 \%, 254 \mathrm{~nm}$ UV radiation diminishes in treated air). Microorganism inactivation by UV radiation (Serratia marcescens) depends on relative air humidity (Riley, 1972). A relative humidity of $100 \%\left(37^{\circ} \mathrm{C}\right.$, $5 \% \mathrm{CO}_{2}$ ) is only obtained inside an incubator, affecting Petri dish content. The bactericidal action of UV radiation is influenced both by relative humidity and by air velocity (Rentschler and Nagy, 1942).

- Operation time is another important factor, since there is always a drop in lamp performance, which differs depending on the make.

- Vertical and horizontal wall surfaces influence the degree of radiation reflection, that is, disinfection levels and potential exposure. 
White epoxy enamel, both VOC-free and watersoluble, is used in laboratory environments to avoid the exposure of workers and embryos to COVs. The absence of COV emissions helps to reduce the UV radiation- induced ozonization
(Takahashi, 1990) and to improve the environmental stability. Odours and COVs, which might come from outside or from different materials inside the laboratory, are eliminated by means of an activated charcoal filter panel.

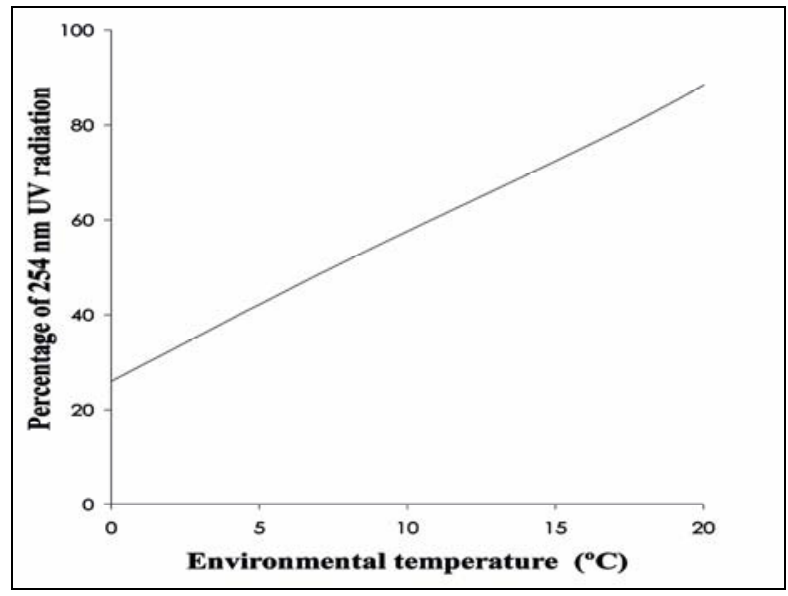

Figure 1 - UV radiation (\%), environmental temperature $\left({ }^{\circ} \mathrm{C}\right)$ and air velocity $(0.5 \mathrm{~m} / \mathrm{s})$ relation.

\section{Control of biological and chemical agents: IVF laboratory application}

By isolating the laboratory (wall coating), it becomes "impermeable" to chemical filtrations. Epoxy enamel has a relatively low reflection level (5-10\%), making it suitable for use in IVF laboratories since it helps to keep lighting levels low, which is essential for cellular maintenance (Gea, 2002). Although a low reflection level diminishes the volume of treated air, it is a basic factor for controlling the laboratory's physical environment. The degree of directional dependency (specular-diffuse) is not normally regarded as important in the application of UV-C radiation (Kowalski and Bahnfleth, 2000). The processes in which wall coating looses its brightness and colour are partly due to radiation.

Studies (SAFYBI, 1998) involving the active (air sampling) and passive (Petri dishes placed in the corners of the room) monitoring of air, contaminated artificially with an aerosol and a Bacillus subtilis (spores) suspension, at intervals before and after nebulisation and after UV treatment have confirmed the germicidal action of UV radiation. The lethal effects of UV radiation on Staphylococcus aureus have also been described (El- Adhami et al, 1994). This use is recommendable in laboratories where a very low level of microbiological contamination is required.
Experimental testing of methods developed to quantify the effect of UV radiation on $B$. subtilis (spores) fixed to particles has demonstrated that surface disinfection of solid particles (Shama et al, 1994) and isolated spores is indeed possible (Munakata et al, 1991). On the whole, a greater resistance to $254 \mathrm{~nm}$ UV radiation has been detected in fungal spores than in bacteria, resistance to UV radiation being specific for each species.

How the lamps work is discussed in detail in the following section. At any rate, precautions are taken so that the overall illumination intensity is never greater than 50 lux, the normal operating level being 30 lux. Optimum lighting that does not affect the cellular material is used for carrying out other tasks. Due to lamp specifications and wavelength control, ozone formation is avoided. Among the active systems used for the chemical and biological control, ventilation and differential pressure control are foremost (Luscuere, 1998). Both the laboratory and cryopreservation room are positively pressurised and equipped with airtight doors to avoid air entering from the rest of the clinic or exiting from the IVF facilities. The air in the laboratory is renewed 20 times per hour. The facilities attached to the IVF laboratory, such as the anteroom and the operating theatre (INSALUD, 1996), are also pressurized but to a 
lesser extent and in decreasing order (Boone et al, 1999).

There are several filter systems: the first is located in the intake of the laboratory's air conditioning system; the second in the air diffusers; and the last in the incubators. Airborne particles greatly diminish the effectiveness of UV radiation. The reasons for installing filters are therefore wellgrounded: as opposed to biological agents, they interact in the disinfection process (eliminating particles and biological agents) and do not produce chemical compounds that might affect cellular development.

The air-conditioning unit (Fig. 2), which constitutes the first barrier, contains the following filters from intake to fan unit: a clean air filter with a minimum gravimetric efficiency $\geq 90 \%$ G4 (EN 779), a bag filter with a minimum opacimetric efficiency $\geq 80 \%$ F7 (EN 779), an activated charcoal filter (see Table 1) and a bag filter with a minimum opacimetric efficiency $\geq 90 \%$ F8 (EN 779). The activated charcoal filter (suitable for eliminating low-volatile pollutants or those with high molecular weight) chiefly adsorbs neutral odour gases (methyl sulphide, dimethyl disulphide), acid gases (hydrogen sulphide, methyl mercaptan) and neutral odourless gases. The filter is composed of activated coconut shell carbon granules $(50 \%)$ and activated alumina impregnated with $4 \%$ by weight of potassium permanganate. Filter specifications and specific reactivity are shown in Tables 1 and 2.

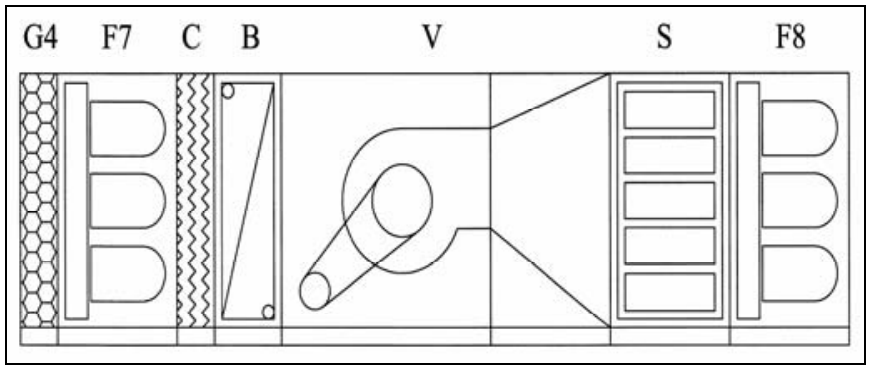

\begin{tabular}{|ll|}
\hline \multicolumn{1}{|c|}{ Legend } \\
\hline G4 & Clean air filter \\
F7 & Bag filter (80\% minimum efficiency) \\
C & Active carbon filter \\
B & Battery \\
V & Fan \\
S & Silencer \\
F8 & Bag filter (90\% minimum efficiency) \\
\hline
\end{tabular}

Figure 2 - Air conditioning unit.

Table 1 - Filter element composition "active carbon"

\begin{tabular}{|c|c|c|}
\hline \multicolumn{3}{|c|}{ A) High quality carbon (50\%) } \\
\hline Specification & Unit & Value \\
\hline Composition (coconut shell) & $\%$ & 100 \\
\hline Iodine & $\mathrm{mg} / \mathrm{g}$ & $>1000$ \\
\hline Moisture (as packed) & $\% \mathrm{wt} / \mathrm{wt}$ & $<3$ \\
\hline Bulk density & $\mathrm{g} / \mathrm{cm}^{3}$ & $0.48-0.51$ \\
\hline Ignition temperature & ${ }^{\circ} \mathrm{C}$ & $>450$ \\
\hline Hardness & $\%$ & $>99$ \\
\hline Surface area & $\mathrm{m}^{2}$ & $>1000$ \\
\hline CTC (carbon tetrachloride adsorption) & $\% \mathrm{wt} / \mathrm{wt}$ & $>60$ \\
\hline Ash content & $\% \mathrm{wt}$ & $<10$ \\
\hline \multicolumn{3}{|c|}{ B) Activated alumina (50\%) } \\
\hline Specification & Unit & Value \\
\hline & & $>5.69(<10 \%)$ \\
\hline Size & $\mathrm{mm}$ & $5.69-2.36(85 \%)$ \\
\hline & & $<2.36(<5 \%)$ \\
\hline Colour & --- & Purple \\
\hline Bulk density & $\mathrm{kg} / \mathrm{m}^{3}$ & 800 (at $15 \%$ moisture) \\
\hline Potassium permanganate & $\%$ by weight (dry) & 4 \\
\hline Moisture content & $\%$ & 20 (maximum) \\
\hline
\end{tabular}


Table 2 - Contaminant reactivity panel.

\begin{tabular}{lll}
\hline \multicolumn{1}{c}{ Highly reactive } & \multicolumn{1}{c}{ Reactive } & \multicolumn{1}{c}{ Less reactive } \\
\hline $\mathrm{SO}_{3}$. & $\mathrm{HCl}$. & Keytones. \\
Ethylene (olefins). & Short-chain alcohols. & Heavy organic vapours. \\
$\mathrm{SO}_{2}$. & Light organic vapours. & Heavy mercaptans. \\
Formaldehyde. & Inorganic acids. & Paraffins. \\
$\mathrm{H}_{2} \mathrm{~S}$. & Chlorine. & Aromatics. \\
$\mathrm{Methyl/} \mathrm{Ethyl} \mathrm{mercaptans.}$ & Organic acids. & Chlorinated hydrocarbons. \\
& Aldehydes. & Long-chain alcohols.
\end{tabular}

The air diffusers (painted with white epoxy, $\mathrm{L}_{\mathrm{w}}=$ $35 \mathrm{~dB})$, attached to the ceiling, are fitted with high efficiency particulate air (HEPA)-type filters, with an efficiency $\geq 99.95 \%$ most penetrating particle size (MPPS) H13 (EN 1822), thus constituting the second filter barrier (ISO, 1998). There is also a third very specific filter barrier located in the incubators, this being a chemical filter for eliminating carbonic gas. It is important to mention the use of temporary barriers in processes involving the direct manipulation of embryos, such as class 100 filters (M 3.5) (US FED STD. 209 E) fitted to the flow boxes with heated and thermally heated surfaces in all the embryo or follicular liquid work areas. Laboratory furniture is made completely of glass, even in the semen processing and embryo freezing areas to avoid the glare.
Should technical problems arise, the laboratory has a start-up protocol. As already mentioned, a sterilised environment can only be achieved if the room in question is hermetically sealed and completely subjected to $254 \mathrm{~nm}$ UV radiation. The object is to reduce the number of micro-organisms to a minimum. The lamps are installed between the first filter barrier and the HEPA-type filter, with the aim of reducing maintenance costs. The germicidal action of the radiation on airborne organisms depends on how long the air is treated (retained). Not all micro-organisms have the same level of resistance: for instance, A. niger spores are 44 times more resistant than E. coli. From a clinical point of view, the most relevant biological environmental agents are shown in Table 3.

Table 3 - Relevant biological agents in the I.V.F. laboratory

\begin{tabular}{ll}
\hline Bacterium & \\
- Clostridium difficile & - Staphylococcus aureus \\
- Clostridium perfringens & - Staphylococcus epidermitis \\
- Escherichia coli & - Streptococcus faecalis \\
- Pseudomonas aeruginosa & - Streptococcus viridans \\
- Serratia marcescens & \\
\hline Fungi & \\
- Aspergillus fumigatus & \\
- Rhizopus spp. & \\
- Mucor spp. & \\
\hline Yeast & \\
- Candida albicans & \\
\hline Virus & \\
- Rotavirus
\end{tabular}

\section{Design, adoption and maintenance of UV air disinfection systems}

Figure 3 shows the dimensions of the laboratory and the cryopreservation room, with a ceiling height of 2.5 metres. The resulting volume of the laboratory is $200.25 \mathrm{~m}^{3}$, the disinfected air volume per minute and per watt $254 \mathrm{~nm} \mathrm{UV}$ being as follows:
$\mathrm{V}=\mathrm{a} \times \mathrm{b} \times \mathrm{c}=1.6 \times 1.2 \times 1.06=2.03 \mathrm{~m}^{3}$, in which

$\mathrm{a}=$ correction factor for a $254 \mathrm{~nm}$ UV radiation reflection of $65 \%$ (treated aluminium air ducts); $\mathrm{b}=$ conduction value in which Escherichia coli inactivation of $99.99 \%$ takes place (cubic metre of air per minute and per watt $254 \mathrm{~nm}$ UV); $\mathrm{c}=$ conduction correction factor. 
Air flow: $4,100 \mathrm{~m}^{3} / \mathrm{h}$.

Relative humidity in the laboratory: $55 \%$.

The amount of $254 \mathrm{~nm}$ UV energy required is

$$
\frac{68.3 \mathrm{~m}^{3} / \mathrm{min}}{2.03 \mathrm{~m}^{3}}=34 \mathrm{w} \text {. }
$$

With an air velocity of $0.5 \mathrm{~m} / \mathrm{s}$ and an environmental temperature of $20^{\circ} \mathrm{C}$, standard $30 \mathrm{w}$ UV lamp performance is approximately $90 \%$ of the nominal value $(9 \mathrm{w})$. For an average lamp use of $2,500 \mathrm{~h}$, the amount of $254 \mathrm{~nm} \mathrm{UV}$ radiation and its germicidal action both diminish by $85 \%$ after 100 hours of use. The average service life of a UV lamp is estimated in 3,000 h (established value for an average of 3 hours use per ignition).

The radiant flux of this kind of lamp is $0.85 \times 0.9 \times 9=6.9 \mathrm{w}(254 \mathrm{~nm} \mathrm{UV})$,

so the number of lamps needed, with similar characteristics as the one mentioned above, is calculated by dividing the amount of energy required by the radiant flux, which gives a value of 4.92. Taking into account the potential variables (dust, suspension particles, etc.), the estimated value is 5. In this way, having calculated the number and type of lamps needed, a disinfection of $99.99 \%$ for E. coli inactivation is guaranteed (at the main duct inlet).

The ventilation system functions continuously (recirculating 20 volumes per hour), with a $20 \%$ contribution of outside air and sufficient efficiency in COV control, filter maintenance and $254 \mathrm{~nm}$ UV air disinfection. Air renovation is way over 50 $\mathrm{m}^{3} / \mathrm{h} /$ worker, the work surface being greater than 2 $\mathrm{m}^{2}$ and the volume greater than $10 \mathrm{~m}^{3} /$ worker.

The radiation system basically consists of a lampholder, lamp, reactance and starter switch. There is also a timer system for regulating radiation emissions in the laboratory. With the exception of nocturnal emissions (absence of influence) for the rest of the day exposure (quasiirrelevant) is defined according to the criteria established (TLVs) by ACGIH, all independent of lamp reflector performance (greater security threshold), enamel epoxy reflection levels, while taking into account a maximum exposure of $8 \mathrm{~h}$ per day. During radiation, both a pilot light on the lamp itself and another outside the laboratory in the changing rooms are activated.

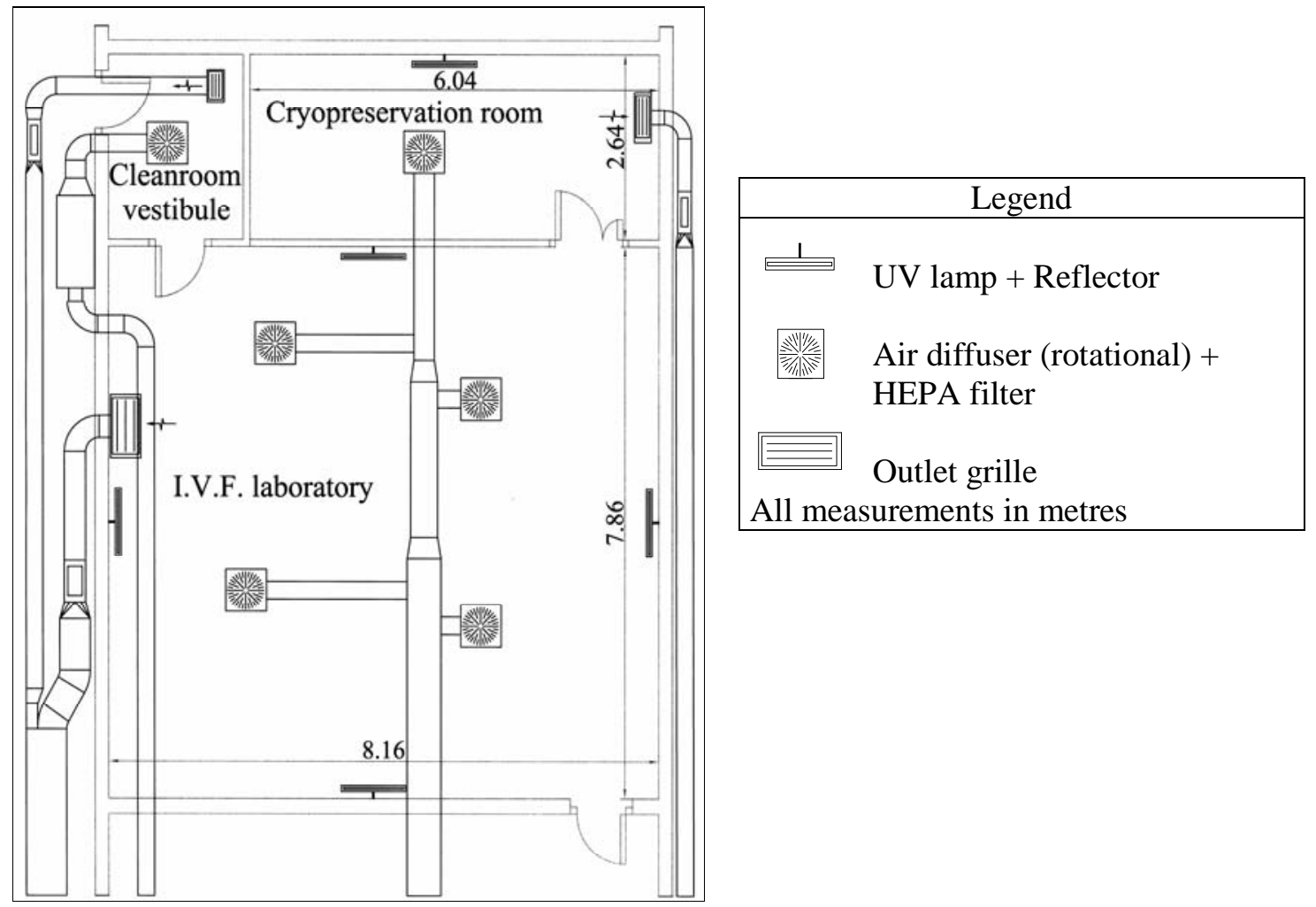

Figure 3 - IVF laboratory and attached facilities. 
The laboratory UV lamps and their aluminium reflectors (up to five depending on the size of the IVF laboratory and the cryopreservation room) are placed at a height of $2.05 \mathrm{~m}$ (Fig. 3), in temporary substitution of those installed in the main air duct or even as a back-up (greater level of asepsis, normal ignition rate at moments of maximum demand). The lamps in the main air duct are placed in easily accessible chambers to facilitate the maintenance and their correct longitudinal orientation in relation to airflow, which goes a long way to reduce the microbial load (Fink et al, 2002). The irradiated air close to the ceiling is usually made to descend due in part to convection, thus promoting air exchange and the consequent reduction of airborne microbes. Heaters and other heat sources have a significant impact on air movement.

The positioning of reflectors on the walls (Fig. 3) improves the radiation effectiveness, since in this way, unnecessary obstacles and the lack of air movement close to the ceiling (due to flat surfaces) are avoided, as well as facilitate cleaning and maintenance. This is important since dust deposition is the main cause of decreasing lamp performance. A mop dampened with alcohol or a mixture of ammonia and water should be used for cleaning, but never polish or oil-based cleaning agents. Lamps are cleaned on a weekly basis and their nominal value (w) tested with a UV meter every fortnight, before cleaning and after 15 minutes of operation.

\section{DISCUSSION}

In relation to the potential impact of different chemical agents on IVF laboratory workers, there is no clear evidence from the studies conducted to date (styrene, acrolein) (TLV's) (Gea, 2002). On being a very specific and delicate application, it is impossible to reach any categorical or overall conclusions as regards their incidence on embryos, particularly when taking into account the high toxicity of acrolein and its effect on the molecular mechanisms of cellular replication (Hall et al, 1998). Certain COVs can be absorbed by culture media (isopropanol) (Cohen et al, 1997) and even affect the implantation rate (Worrilow et al, 2002). In any case, it would be necessary to conduct a viability study on samples at different concentrations and exposure results, with the controversy that this would provoke. The reasoning of using radiation to control biological agents are evident.

Within the physical agents and with respect to the effect of $254 \mathrm{~nm}$ UV radiation on workers due to the materials used, exposure, effective irradiation and design, according to ACGIH guidelines, commonly known as TLVs, risks are non-existent. The unique and innovative design of the air conditioning system, along with the filter sections, makes an indispensable contribution towards purifying air, both physically and chemically. The synergy between the different applications (laboratory and facility design, wall coating, filter system, radiation, control, etc.) helps to create positive environmental conditions for workers and the tasks they carry out. The line of study proposed here ought to be continued so as to better understand the process and discover alternative materials or air treatment systems that favour the elimination of different polluting agents.

\section{RESUMO}

Este estudo dirige-se ao controle ambiental de um laboratório "in vitro fertilization (IVF)" e das repercussões potenciais que a presença de determinados agentes físicos, químicos e biológicos possa ter na saúde nos trabalhadores' ou nas tarefas que se realizem. O projeto do laboratório e de suas facilidades contribui a uma melhoria na qualidade do trabalho e minimiza riscos ambiental-relacionados. As medidas preventivas adotadas têm uma influência nas ações realizadas.

\section{REFERENCES}

American Conference of Governmental Industrial Hygienists (ACGIH). (1998), TLVs Valores límite para sustancias químicas y agentes físicos en el ambiente de trabajo. BEIs Indices biológicos de exposición. Generalitat Valenciana. Seguridad y Salud en el Trabajo. 36.

Bintsis, T., E. Litopoulou-Tzanetaki, and R.K. Robinson. (2000), Existing and potential applications of ultraviolet light in the food industry- a critical review. J. of the Science of Food and Agriculture. 80, 637-645.

Boone, W. R., Johnson, J. E., Locke, A. J., M. M. Crane, and T. M. Price. (1999), Control of air quality in an assisted reproductive technology laboratory. Fertility and Sterility. 71 (1):150-154. 
Cohen, J., Gilligan, A., Esposito, W., T. Schimmel, and B. Dale. (1997), Ambient air and its potential effects on conception. Human Reproduction. 12 (8), 17421749.

El-Adhami, W., S. Daly, and P. R. Stewart. (1994), Biochemical studies on the lethal effects of solar and artificial ultraviolet radiation on Staphylococcus aureus. Arch. Microbiol., 161, 82-87.

Fink, R. G., Ellis, W., Hart, J. A., C. Pearsall, and S. Rinehimer. (2002), Photo- ionisation as an antimicrobial. International Food Hygiene. 13 (4), 57.

Gea Izquierdo, E. (2002), Incidencia del estireno y la acroleína en la viabilidad de muestras biológicas: Presentación del estudio realizado en un laboratorio F.I.V. Ingeniería Hospitalaria. 24.

Hall, J., Gilligan, A., Schimmel, T., M. Cecchi, and J. Cohen. (1998), The origin, effects and control of air pollution in laboratories used for human embryo culture. Human Reproduction. 13 (4), 146- 155.

Heinsohn, R,J., Spaeder, T. A., Albano, M.T., J.P. Schmelzle, and R.O. Fetter. (1994), Ultraviolet and radical oxidation of airborne VOC's. Environmental Engineering: Air Pollution and Control. Mar.

Ichiura, H., T. Kitaoka, and H. Tanaka. (2003), Removal of indoor pollutants under UV irradiation by a composite $\mathrm{TiO}_{2}$-zeolite sheet prepared using a papermaking technique. Chemosphere. 50 (1).

INSALUD. (1996), Guía práctica para el diseño y mantenimiento de la climatización en quirófanos. Ministerio de Sanidad y Consumo. Instituto Nacional de la Salud.

INSALUD. (1999), Sociedad Española de Medicina Preventiva, Salud Pública e Higiene. Recomendaciones para la verificación de la bioseguridad ambiental (BSA) respecto a hongos oportunistas.

International Organization for Standardization: ISO/DIS 14644-4. (1998),Cleanrooms and associated controlled environments- Part 4: Design and construction.

Klánová, K. (2003), Hospital indoor environment: screening for micro- organisms and particulate matter. Indoor and built environment. 12 (1,2), 61-67.

Kowalski, W. J., and W.P. Bahnfleth. (2000), UVGI design basics for air and surface disinfection. HPAC Engineering. Jan.

Luscuere, P.G. (1998), Indoor air quality in hospitals. $J$. Rehva. 1, 6-14.

Morgan, R.: "Green" light disinfection. (1989), J. Dairy-Industries- International. 54 (11), 33-35.

Munakata, N., M. Saito, and K. Hieda. (1991), Inactivation action spectra of Bacillus subtilis spores in extended ultraviolet wavelengths (50-300 nm) obtained with synchrotron radiation. Photochem. and Photobiol., 54 (5), 761-768.
Philips. (1985), Germicidal lamps and applications. Philips Lighting Div.

Real Decree no 486 - 1997; April 14, 1997. (Real Decreto 486/1997, de 14 de abril, por el que se establecen las disposiciones mínimas de seguridad y salud en los lugares de trabajo).

Rentschler, H.C., and R. Nagy. (1942), Bactericidal action of ultraviolet radiation on air-borne organisms. J. Bacteriol., Jul.; 44 (1), 85-94.

Riley, R.L.K. (1972), Effect of relative humidity on the inactivation of airborne Serratia marcescens by ultraviolet radiation. Applied Microbiol., 23 (6), 1113-1120.

SAFYBI. (1998), Método de desinfección del aire. Eficiencia de la luz ultravioleta. Nuevas perspectivas. Boletín Informativo. 229.

Santos Nogueira, A,C., and I. Joekes. (2004), Hair color changes and protein damage caused by ultraviolet radiation. J. Photochem. Photobiol. B., May; 74 (2-3), 109-117.

Scheir, R., and F. B. Fencl. (1996), Using UVC Technology to Enhance IAQ. HPAC. Feb.

Shama, G., Gardner, D. W. M., A. P. Martin, and N. L. Mason. (1994), Disinfection of particles using ultraviolet light. Trans IchemE., 72(C4), 197-200.

Takahashi, N. (1990), Ozonation of several organic compounds having low molecular weight under ultraviolet irradiation. Ozone Science and Engineering. 12, 1-17.

Wiemer, K.E., A. Anderson, and B. Stewart. (1998), The importance of water quality for media preparation. Human Reproduction. 13 (4), 166-172.

Worrilow, K. C., H. T. Huynh, and A. J. Peters. (2000), The innovative marriage between cleanroom and assisted reproductive technologies (ART)- The design, construction and National Environmental Balancing Bureau (NEBB) certification of a prototype class 100/class 10 IVF laboratory cleanroom. Fertility and Sterility. 74 (1).

Worrilow, K. C., Huynh, H. T., Bower, J. B., W. Schillings, and A.J. Peters. (2002), A retrospective analysis: seasonal decline in implantation rates (IR) and its correlation with increased levels of volatile organic compounds (VOC). Fertility and Sterility. 78 (1).

Worrilow, K. C., Huynh, H. T., Gwozdziewicz, J. B., W.A. Schillings, and A.J. Peters. (2001), A retrospective analysis: the examination of a potential relationship between particulate $(\mathrm{P})$ and volatile organic compound (VOC) levels in a class $100 \mathrm{IVF}$ laboratory cleanroom $(\mathrm{CR})$ and specific parameters of embryogenesis and rates of implantation (IR). Fertility and Sterility. 76 (1)

Received: June 22, 2007; Revised: December 14, 2007; Accepted: January 19, 2009 